\section{Assessing the physical health of psychiatric patients}

Sir: $33.5-80 \%$ of psychiatric patients suffer from physical illness requiring treatment (Hall et al, 1981). About half of these physical illnesses were unrecognised, and may cause or exacerbate the psychiatric disorder. It is therefore vital that all psychiatric patients are screened for physical disorders.

A survey of 100 in-patient case notes in five acute psychiatric and two psychogeriatric wards, found that only 13 were asked about physical symptoms, two of which performed a comprehensive review of systems or systematic enquiry. Nintey-one patients had some form of physical examination and 93 had laboratory investigations. This pattern of practice is inconsistent with the medical doctrine, substantiated by research, that most diagnoses can be made with the history alone.

Virtually all 'physicals' did not include the endocrine or locomotor system, and over half the nervous system examinations were cursory observations. Eighty-one patients had their blood pressures measured. Thirty-two had hypertension but only four were followed up.

We support Osborn \& Warner's (Psychiatric Bulletin, November 1998, 22, 695-697) view that a symptom review should be used as the screening tool for physical illness in psychiatric patients, since psychiatrists are uniformly poor at performing physical examinations (Rigby \& Oswald, 1987). Even if abnormalities are found, appropriate action may not be taken.

A systematic enquiry of physical symptoms will also identify somatic aspects of psychiatric disease. It is probably less time-consuming and more cost-beneficial than blind physical examinations and random tests. Hence, the concept of taking a physical history before performing the relevant examinations should be inculcated in psychiatrists.

\section{References}

HALL, R. C. W., GARDNER, E. R., POPKIN, M. K., et al (1981) Unrecognised physical illness prompting psychiatric admission: a prospective study. American Journal of Psychiatry. 138, 629-635.

OSBORN, D. P. J. \& WARNER. J. P. Assessing the physical health of psychiatric patients. Psychiatric Bulletin, 22. 695-697.

RigBY, J. C. \& OSWALD. A. G. (1987) An evaluation of the performing and recording of physical examination of psychlatric trainees. British Journal of Psychiatry. 160. 533-535.

MAW-PIN TAN, Pre-Registration House Officer; and *DAvid G. TOMBS, Consultant Psychiatrist, The Psychiatric Unit, Derby City General Hospital, Uttoxeter Road, Derby DE22 3NE

*Correspondence

\section{PRN prescribing and administration of antimuscarinic medication}

Sir: The prophylactic use of antimuscarinic medication for those on long-term antipsychotic drugs is not recommended (World Health Organization, 1990). However, psychiatric in-patients may still receive substantial amounts of antimuscarinic medication via the less well regulated 'as required' (p.r.n.) route.

A recent survey of psychiatric nursing staff opinions about the use of p.r.n. antimuscarinic medication suggests that guidelines for nursing staff who administer these drugs would be helpful. We approached a cross-section of qualified nursing staff working on adult inpatient psychiatric units in the West Midlands, and asked them to complete a questionnaire about anitmuscarinic medication. Thirty-six of the 37 qualified members of nursing staff on duty on the day the study was conducted agreed to participate.

Nursing staff emphasised the importance of objective assessment for antipsychotic induced side-effects prior to dispensing a p.r.n. dose of antimuscarinic medication. They also demonstrated a good working knowledge of acute extrapyramidal side-effects, however, many also said they would give antimuscarinic drugs for other reasons. Fifteen subjects (42\%) said they would give p.r.n. procyclidine to a patient complaining of dry mouth, and 13 (36\%) said they would give it for blurred vision. These commonly encountered side-effects will be worsened by antimuscarinic drugs. Furthermore, 17 nurses (47\%) said that it would be appropriate to treat repetitive chewing movements caused by antipsychotic medication (tardive dyskinesia) with antimuscarinic drugs. Antimuscarinic drugs do not improve tardive dyskinesia, indeed there is evidence that they may precipitate it and exacerbate it (Ebel, 1994; Barnes \& Phillips, 1996).

We conclude that no assumption should be made that antimuscarinic agents, prescribed on an 'as required' basis for extrapyramidal sideeffects, will necessarlly be dispensed according to these instructions. When reviewing the need for an 'as required' prescription, the nature of the side-effects for which antimuscarinic medication is being given should always be clarified.

To address our findings, we produced a set of guidelines for nursing staff on the use of 'as required' antimuscarinic medication. The inpatient units who were surveyed now have these guidelines on display in the form of an A4 size, laminated poster located in the nursing office and the dispensing area. The response from nursing staff to this intervention has been very encouraging. 


\section{References}

BARNes, T. R. E. \& PHILuPS, M. A. (1996) Antipsychoticinduced extrapyramidal symptoms. Role of anticholinergic drugs in treatment. CNS Drugs, 6. 315-330.

EBEL, H. (1994) Therapy of neuroleptic-induced extrapyramidal movement disorders. Neurology Psychiatry and Brain Research, 2, 140-151.

WORLD HEALTH ORganization Heads OF CENTRE COLlaborating IN WHO COORDINATED STUdies ON BIOLOGICAL ASPECTS OF MENTAL ILLNESS (1990) Prophylactic use of anticholinergics in patients on long-term neuroleptic treatment. A consensus statement. British Journal of Psychiatry, 166, 412.

LUKE BIRMINGHAM, Lecturer in Forensic Psychiatry; NORMAN MCCLELLAND, Lecturer in Forensic Nursing; and CAROLINE BRADLEY, Specialist Registrar in Forensic Psychiatry, University of Birmingham, Department of Forensic Psychiatry, Reaside Clinic, Birmingham Great Park, Bristol Road South, Birmingham B45 9BE

\section{Easing the medical staffing crisis in poychiatry}

Sir: Jenkins \& Scott (Psychiatric Bulletin, April $1998,22,239-241)$ have correctly drawn attention to the current crisis. An important factor in psychiatry is the ability of consultants to retire at
55 years of age, often reaching maximum pension at 57-58 years of age. As work in general psychiatry is currently highly stressful, most consultants choose to retire on reaching maximum pension or earlier. They then spend their time providing second opinions for the Mental Health Act Commission and attending mental health review tribunals; a worthy occupation. but not 'real' psychiatry.

However, my own experience may be of interest to consultants considering retirement. Having retired at 58 years of age I have been able to continue working five sessions per week in my own psychiatric unit and by chance found an additional part-time consultant who wanted to 'job-share'. Though for five sessions my combined earnings plus pension equal my previous salary, this is at no extra cost to the unit and between us we are carrying out all the duties of my former consultant post. Work which before seemed onerous I can now take in my stride and hope to continue to do so for some years.

Clearly, the arrangement allowing me to continue working within my own unit and even in my own catchment area required some flexibility on the part of my employing trust, but if this arrangement were widely adopted it may help to ease the shortage of consultants.

ERIC BIRCHALl, Consultant Psychiatrist, University Hospital Aintree, Liverpool L9 7AL 